\title{
Physician burnout among West Virginia primary care providers
}

\author{
Kevin S. McCann, MD', Adam Baus, PhD²
}

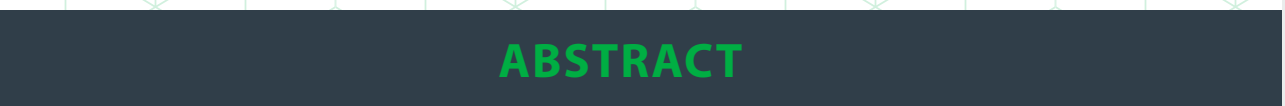

Work-related burnout is highly prevalent in US physicians and linked to adverse effects on patients, providers, and organizations. This study measures burnout in West Virginia (WV) primary care providers, allowing for comparison of results to a similar, recent study of US physicians. The study population consisted of 110 subjects who were either primary care physicians (PCP) or advanced practice registered nurses/physician assistants (APRN/PA). Anonymous survey was sent through email, which included Maslach Burnout Inventory, demographic, workload, and practice characteristics. Responses were analyzed using JMP Pro 13. Analysis used JMP Pro 13 for descriptive statistics, chi-square, and regression modeling. PCP and APRN/PA differed on sex ratio. The OR for severe burnout in primary care providers $\geq>/=65$ vs under 65 was 0.178 . Severe burnout in WV PCPs was higher than in all US physicians. The OR for severe burnout in PCPs versus APRN/ PAs was 2.89. Burnout in PCPs > APRNs in rural but not urban areas. Private practice consisted of $17.6 \%$ in our population versus $48 \%$ in US physicians. Burnout increased linearly with work hours. Self-estimate of burnout correlated with MBI results. Severe burnout was highly prevalent in this high-risk specialty serving a patient population at risk in regards to poverty, age, and medical complexity. This community had a low rate of private practice, fewer providers over age 65 , a higher rate of burnout in physicians compared to APRN/PA, and a linear association of burnout to work hours. A single-question burnout-screening tool was also validated. High-risk community systems could be a reservoir for burnout research and improvement there could reduce costs and improve outcomes.
Author affiliations are listed at the end of this article.

Correspondence to: Kevin S McCann, MD Marshall University Joan C. Edwards School of Medicine mccann2@marshall.edu

\section{KEYWORDS}

Burnout, Primary Care, Rural, Provider Type, Practice Type

\section{METHODS}

Anonymous survey through email that included Maslach Burnout Inventory, demographic, workload, and practice characteristics. Responses were analyzed using JMP Pro 13. Analysis used JMP Pro 13 for descriptive statistics, chi-square, and regression modeling.

\section{RESULTS}

The study population consisted of 110 subjects who were either primary care physicians (PCP) or advanced practice registered nurses/physician assistants (APRN/PA), all primary care physicians (PCP), or advanced practice registered nurses or physician assistants (APRN/PA). PCP and APRN/PA differed on sex ratio $(p<0.0005)$. The OR for severe burnout in primary care providers $\geq>/=65$ vs under 65 was 0.178 $(p=0.032)$. Severe burnout in WV PCPs was $57.6 \%$ and in all US physicians $43.9 \%(p=0.015)$. The OR for severe burnout in PCPs versus APRN/PAs was 2.89 ( $p$ $=0.039)$. Burnout in PCPs $>$ APRNs in rural $(p=0.046)$ but not urban areas. Private practice consisted of $17.6 \%$ in our population versus $48 \%$ in US physicians $(p=0.0003)$. Burnout increased linearly with work hours ( $p=0.003$ ). Self-estimate of burnout correlated with $\mathrm{MBI}$ results $(p<0.0001)$.

\section{CONCLUSION}

Severe burnout was highly prevalent in this highrisk specialty serving a patient population at risk in regards to poverty, age, and medical complexity. This community had a low rate of private practice, fewer providers over age 65 , a higher rate of burnout in physicians compared to APRN/PA, and a linear association of burnout to work hours. A single-question burnout screening tool was also validated. High-risk community systems could be a reservoir for burnout 
research and improvement there could reduce costs and improve outcomes.

\section{INTRODUCTION}

The American Medical Association defines burnout as a long-term stress reaction. ${ }^{1}$ The concept of burnout in healthcare providers has been described since the $1970 s^{2}$ and was pioneered by Christina Maslach, the developer of the most frequently used measure of burnout, the Maslach Burnout Inventory (MBI). ${ }^{3}$ The MBI scoring provides a three-dimensional measure of human feeling that correlates with perceived workplace strain. The three areas of feeling measured are emotional exhaustion, depersonalization, and personal accomplishment, which tell us how much the worker feels drained by their work, how hard or cynical they have become, and how efficacious they feel, respectively.

Burnout is important because it is associated with adverse effects on patients, providers, and health systems. The adverse consequences for patients include increased medical error, ${ }^{4-8}$ reduced professionalism, ${ }^{5}$ and a reduction in patient satisfaction. ${ }^{5,9}$ Provider health effects of burnout are evident in higher rates of cardiovascular disease and shorter life expectancy, ${ }^{10}$ a higher rate of suicidal ideation and depression, ${ }^{11-15}$ substance abuse, ${ }^{13}$ and divorce. ${ }^{13}$ The economic impact on institutions related to burnout involves expenses related to turnover and reduced productivity, ${ }^{16-23}$ as well as additional costs related to medical errors. ${ }^{24}$ There are numerous drivers of physician burnout, including factors that arise external to or intrinsic to the provider, and some of which likely operate in a bidirectional manner. External factors include imposed rules and regulations, ${ }^{25}$ electronic medical records, ${ }^{25-27}$ negative workplace quality and safety culture, ${ }^{28}$ reduced autonomy, ${ }^{28}$ constraining organization structures, ${ }^{28}$ pressure for productivity, ${ }^{25}$ increased workload, ${ }^{28,29}$ negative attitudes of cowork$\mathrm{ers}^{28}$ the medical education process, ${ }^{30}$ and barriers to mental healthcare such as disclosure to licensing boards. ${ }^{31}$ Internal factors include the perception that high-quality medical care is not being delivered, ${ }^{25}$ work-life conflicts, ${ }^{28,29}$ personality traits, ${ }^{32}$ lack of both self-compassion and mindfulness, ${ }^{33}$ being in mid-career, ${ }^{34}$ being a resident physician,, 14 and working in a medical field with frontline access to care such as primary care or emergency room. ${ }^{35}$
Our research group selected burnout as a high-priority research topic for our region. Our goals were to assess whether burnout was more prevalent in West Virginia and identify factors that were associated with burnout here.

\section{METHODS}

This study was designed and conducted by the West Virginia Alliance for Creative Health Solutions (WVACHS), an interdisciplinary group of clinicians, administrators, and researchers working to address priority health needs in West Virginia. ${ }^{36}$ The goal of this research was to measure the level of burnout in West Virginia primary care providers, allowing for comparison to results from a similar study ${ }^{37}$ of US physicians at approximately the same time (Fall 2017). We solicited subjects through email listservs of the Family Medicine Foundation of West Virginia, the West Virginia Academy of Family Physicians, and the West Virginia Primary Care Association. Subjects were provided a link inviting them to complete an anonymous survey that obtained demographic data, workload, and practice characteristics, along with the Maslach Burnout Inventory (MBI), ${ }^{38}$ which is a validated, accepted tool for measuring provider burnout (Appendix 1). The appendix includes the map that was used to help the subjects determine if their practice was in a rural or urban area. Quantitative data analysis was conducted using JMP Pro 13. Descriptive statistics, chi-square tests, and regression modeling were used to describe the data and relationships across variables.

This study was approved by the Institutional Review Board of Marshall University, Huntington, West Virginia (IRB number 1032508-4). Funding for this study was provided by a grant from the Claude Worthington Benedum Foundation and the West Virginia Higher Education Policy Commission to conduct the research.

\section{RESULTS}

\section{DEMOGRAPHIC AND PRACTICE CHARACTERISTICS}

There were 110 completed surveys returned. Respondents were primarily female ( $57.3 \%)$, between the ages of 35 and 64 (74.5\%). There was an almost equal 
distribution of providers between the ages of 35 to $44(24.5 \%), 45$ to $54(24.5 \%)$, and 55 to $64(25.4 \%)$. Only $10 \%$ of all respondents were age 65 and older. Among all respondents, $77.3 \%$ were physicians, $19.1 \%$ were advanced practice registered nurses, and $3.6 \%$ were physician assistants. Given the lower number of advanced practice registered nurses and physician assistants represented in this study, these groups were combined and are hereafter referred to as (APRNs/PAs) (22.7\%). In this study, $53.6 \%$ of respondents practice in urban locations as identified by the US Census Bureau. Respondents tend to practice in federally qualified health centers (30.9\%), followed by academic medical centers $(22.7 \%)$, private practic-

TABLE 1. Demographic and practice characteristics for survey respondents.

\begin{tabular}{|c|c|c|c|}
\hline Category & Sub-categories & Number $\mathrm{N}=110$ & Percent \\
\hline \multirow[t]{3}{*}{ Gender } & Female & 63 & 57.3 \\
\hline & \begin{tabular}{|l|} 
Male \\
\end{tabular} & 46 & 41.8 \\
\hline & Prefer not to say & 1 & 0.9 \\
\hline \multirow[t]{5}{*}{ Age } & $<35$ & 17 & 15.4 \\
\hline & $35-44$ & 27 & 24.5 \\
\hline & $45-54$ & 27 & 24.5 \\
\hline & \begin{tabular}{|l|}
$55-64$ \\
\end{tabular} & 28 & 25.4 \\
\hline & 65 and above & 11 & 10.0 \\
\hline \multirow[t]{3}{*}{ Provider Type } & APRN & 21 & 19.1 \\
\hline & Physician & 85 & 77.3 \\
\hline & Physician Assistant & 4 & 3.6 \\
\hline \multirow[t]{3}{*}{ Rurality } & Rural & 50 & 45.4 \\
\hline & Urban & 59 & 53.6 \\
\hline & Missing & 1 & 0.9 \\
\hline \multirow[t]{8}{*}{ Practice Type } & Academic & 25 & 22.7 \\
\hline & Federally Qualified Health Center & 34 & 30.9 \\
\hline & Hospital System & 19 & 17.3 \\
\hline & Long Term Care Facility & 2 & 1.8 \\
\hline & Private Practice & 20 & 18.2 \\
\hline & \begin{tabular}{|l|} 
Urgent Care \\
\end{tabular} & 5 & 4.5 \\
\hline & Veterans Facility & 1 & 0.9 \\
\hline & Other & 4 & 3.6 \\
\hline \multirow[t]{3}{*}{ Practice Setting } & Inpatient & 3 & 2.7 \\
\hline & Outpatient & 81 & 73.6 \\
\hline & Inpatient and Outpatient & 26 & 23.6 \\
\hline \multirow[t]{7}{*}{ Average Hours Worked per Week } & $<40$ & 18 & 16.5 \\
\hline & \begin{tabular}{|l|}
$40-49$ \\
\end{tabular} & 42 & 38.5 \\
\hline & \begin{tabular}{|l|}
$50-59$ \\
\end{tabular} & 29 & 26.6 \\
\hline & $60-69$ & 15 & 13.8 \\
\hline & \begin{tabular}{|l|}
$70-79$ \\
\end{tabular} & 4 & 3.6 \\
\hline & 80 or more & 1 & 0.9 \\
\hline & Missing & 1 & 0.9 \\
\hline \multirow[t]{9}{*}{ Years in Practice } & $<5$ & 21 & 19.1 \\
\hline & $5-9$ & 15 & 13.6 \\
\hline & $10-14$ & 12 & 10.9 \\
\hline & $15-19$ & 8 & 7.3 \\
\hline & $20-24$ & 17 & 15.5 \\
\hline & \begin{tabular}{|l|}
$25-29$ \\
\end{tabular} & 17 & 15.5 \\
\hline & \begin{tabular}{|l|}
$30-34$ \\
\end{tabular} & 9 & 8.2 \\
\hline & \begin{tabular}{|l|}
$35-39$ \\
\end{tabular} & 6 & 5.4 \\
\hline & 40 or more & 5 & 4.5 \\
\hline
\end{tabular}




\section{MASLACH BURNOUT INVENTORY RESULTS}

Findings from the Maslach Burnout Inventory offer insights into the current burnout landscape in West Virginia and pinpoint specific provider characteristics important to consider in terms of intervention planning.

In terms of demographic characteristics, differences in severe burnout among female and male providers were not significant (OR 1.05, 95\% Cl: $0.49-2.25)(p=0.89)$. However, we find that primary care providers under the age of $65(55.6 \%)$ have 5.62 times the odds of experiencing severe burnout compared to their older counterparts (18.2\%) (OR 5.62, 95\% Cl: 1.16 - 27.38), $(p=0.01)$ [Table 2].
Regarding provider type, physicians (57.6\%) have 2.89 times the odds of having severe burnout compared to APRNs/PAs (32.0\%) (OR 2.89, $95 \% \mathrm{Cl}: 1.13-7.43),(p=0.023)$ [Table 2]. Overall, physicians have higher levels of burnout in emotional exhaustion, depersonalization, and personal accomplishment. Physicians (50.6\%) were significantly more likely than APRNs/PAs (12.0\%) to score high for emotional exhaustion $\times 2$ (1, $110)=13.36,(p<0.001)$ [Table 3]. In fact, analyzing the combined effects of variables using a nominal logistic fit for severe burnout, provider type was the most influential variable among other factors including hours worked per week, age, gender, rurality, and practice type $\left(R^{2}=.067\right.$, $F(6,110)=10.21)(p=0.116)$. Only the provider type of physician had a significant association

TABLE 2. Provider characteristics in relation to scoring positive for severe burnout.

\begin{tabular}{|llll|}
\hline Category & Variable & OR $(95 \%$ CI $)$ & $p$ Value \\
\hline Gender & Male & 1.0 (Reference) & \\
& Female & $1.05(0.49-2.25)$ & 0.89 \\
\hline Age* $^{*}$ & $>=65$ & 1.0 (Reference) & \\
& $<65$ & $5.62(1.16-27.38)$ & 0.01 \\
\hline Provider Type** & APRN/PA & 1.0 (Reference) & \\
& Physician & $2.89(1.13-7.43)$ & 0.023 \\
\hline
\end{tabular}

"Groups are significantly different $(\mathrm{p}<0.05)$

TABLE 3. Comparison of burnout domains between physician and APRN/PA.

\begin{tabular}{|c|c|c|c|c|c|c|}
\hline Burnout Domain & Provider Type & N High & h N Low & $\begin{array}{r}\% \text { Severe } \\
\text { Burnout }\end{array}$ & $\begin{array}{l}\text { e } X^{2(d f)} \\
\text { t }\end{array}$ & $p$ Value \\
\hline \multirow{2}{*}{$\begin{array}{l}\text { Emotional } \\
\text { Exhaustion* }\end{array}$} & Physician & 43 & 42 & 50.6 & $13.36(110)$ & $<0.001$ \\
\hline & APRN/PA & 3 & 22 & 12.0 & & \\
\hline \multirow[t]{2}{*}{ Depersonalization } & Physician & 31 & 54 & 36.5 & $1.40(110)$ & 0.236 \\
\hline & $\mathrm{APRN} / \mathrm{PA}$ & 6 & 19 & 24.0 & & \\
\hline \multirow{2}{*}{$\begin{array}{l}\text { Personal } \\
\text { Accomplishment } \dagger\end{array}$} & Physician & 73 & 12 & 14.12 & $0.08(110)$ & 0.784 \\
\hline & APRN/PA & 22 & 3 & 12.0 & & \\
\hline
\end{tabular}

"Factors are significantly different. $\dagger$ Severe burnout in personal accomplishment is indicated by a low score. Severe burnout in emotional exhaustion and depersonalization is indicated by a high score. 


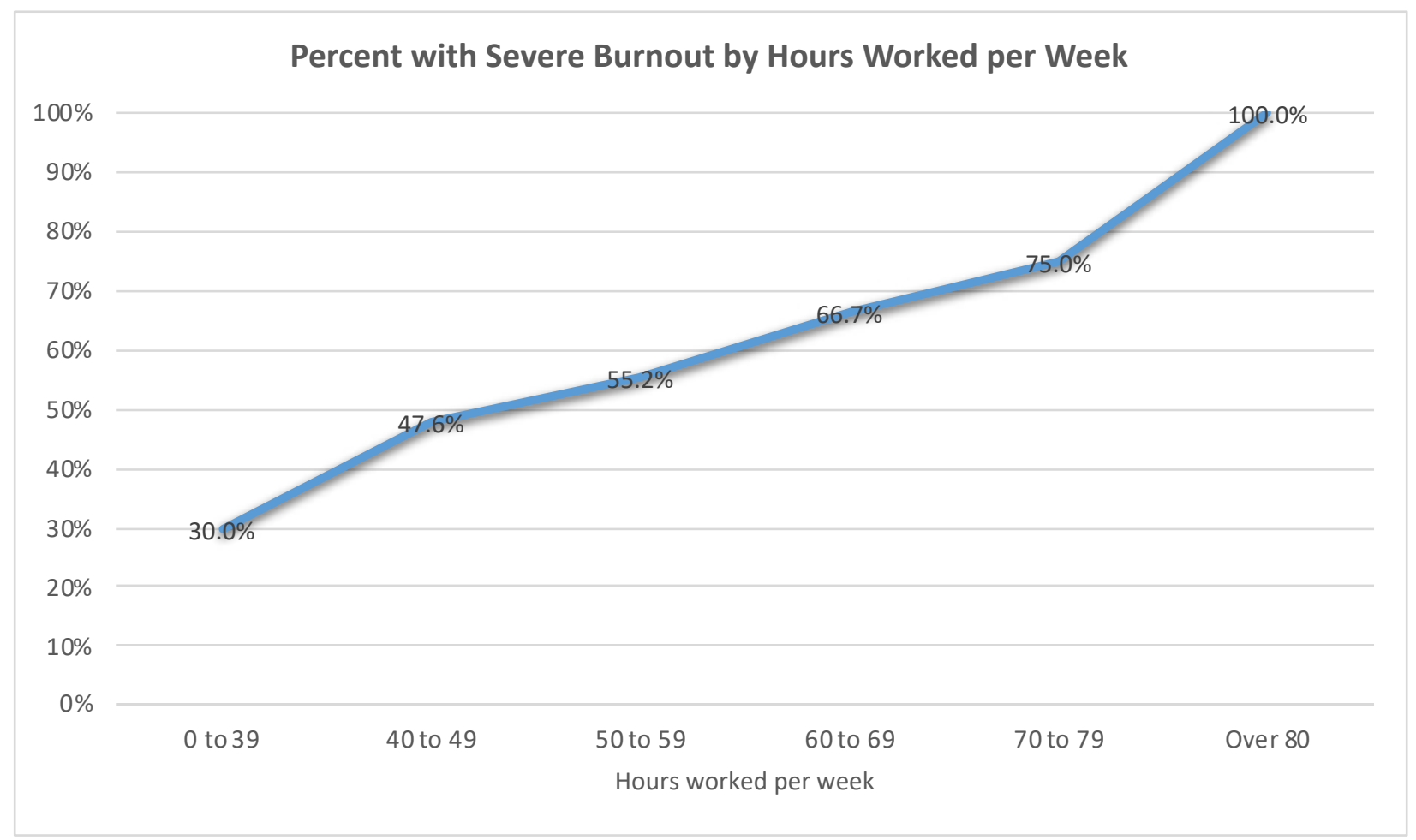

FIGURE 1. Percent of respondents with severe burnout by hours worked per week.

( $p=0.0179$ ). Differences among physicians and APRNs/PAs in depersonalization (OR 1.82, 95\% Cl: $0.66-5.03),(p=0.23)$ and personal accomplishment (OR 1.20, 95\% Cl: $0.31-4.66),(p=$ 0.78 ) were not significant.

Severe burnout was present in $58.0 \%$ of rural providers and $47.5 \%$ of urban providers $\times 2(1$, $109)=1.21(p=0.27)$. Among physicians, severe burnout was present in $66.7 \%$ of rural physicians and $50.0 \%$ of urban physicians $\times 2(1,85)=2.42$ $(p=0.12)$. In neither of these cases were the differences significant. There was a significant difference, however, in severe burnout among rural physicians (66.7\%) compared to rural APRNs/PAs $(27.3 \%) \times 2(1,50)=5.49(p=0.02)$. This difference was not significant in urban areas $\chi^{2}(1,59)$ $=0.55(p=0.46)$.

The number of hours worked per week is an important factor for provider wellbeing. There was a clear linear association between increasing work hours and severe burnout [Figure 1]. Furthermore, there was a linear increase in emotional exhaustion as work hours increase $F$ $(1,88)=11.85$, $(p<0.001)$. Comparatively, depersonalization was not significant $F(1,88)=0.82$, $(p=0.367)$.

This study found a significant association between subjects' self-rating of severe burnout and the presence of severe burnout. Respondents who rated themselves as having severe burnout had 2.04 times the average risk of scoring positive for severe burnout on the MBI compared to those who did not rate themselves as having severe burnout (RR 2.04, 95\% Cl: 1.68 - 2.48) ( $p$ $=0.004$ ). There was no significant association between willingness to participate in a burnout intervention and burnout severity $\times 2(1,109)=$ 1.03, $(p<0.310)$.

\section{COMPARISON BETWEEN WEST VIRGINIA AND THE US}

Comparison between West Virginia and the US was only feasible for physician providers. Severe burnout (emotional exhaustion score $>=27$ 
and/or a depersonalization score of $>=10$ ) was present in $57.6 \%$ of primary care physicians in West Virginia vs. $43.9 \%$ of US physicians in general $((p=0.015)$ and $47.96 \%$ of US primary care physicians $(p=0.107)$. There were more female respondents in West Virginia (47\%) vs. the US $(38 \%)(p=0.065)$. The West Virginia physician population was younger than the US $(p=0.047)$. The percentage for West Virginia/US for age under 35 was $11.6 \% / 6.4 \%$ and age 65 or above $8.24 \% / 18.3 \%$.

\section{DISCUSSION}

The discussion focuses on significant findings, with added contextual information on how the findings relate to previous research, coupled with a discussion of translational implications. It is important to remember that most of the existing information on physician burnout is derived from observational studies which come with the attendant limitation of confounding of variables. ${ }^{39}$ One example of this is the relationship between age and burnout in which there are opposing theories as to which is the cause and which is the effect. ${ }^{34}$

\section{HIGHER BURNOUT IN WEST VIRGINIA THAN IN THE US}

Burnout is higher in West Virginia primary care physicians than in the US as a whole as well as US primary care physicians. However, the difference between West Virginia and US primary care did not quite meet statistical significance $(p=0.107)$. This is the first published comparison of simultaneous measurements of burnout in West Virginia primary care and the US. There is evidence that this is partly explained by demographic differences. Our subjects were significantly more likely to be female and to be younger. Being female ${ }^{37,40,41}$ and being younger ${ }^{37}$ have previously been associated with burnout. We theorize that some of the reasons for higher burnout in West Virginia may be inferred by looking at factors previously associated with burnout that are more prevalent in West Virgin$i a$. The first factor is medical practice in a region that has a high prevalence of poverty, which has been previously associated with burnout in primary care. ${ }^{42,43}$ In 2018, West Virginia had the fourth-highest poverty rate in the US ${ }^{44}$ and West Virginia family medicine physicians had the lowest average annual income of all 50 states in 2020. This could impact burnout rates as providers would have to cope both with a lower personal income and the challenges that their patients face due to financial hardships such as the inability to afford medication and healthy foods, or access transportation, all of which impair the success of medical care of the patient and likely add to the provider's sense of frustration from not meeting treatment goals. The next factor is medical complexity or comorbidity of the population, which has previously been associated with primary care burnout. ${ }^{43}$ There is evidence that the population of West Virginia has high rates of medical comorbidity/ complexity. In 2017, West Virginia ranked first in the US for deaths related to diabetes and accidents, and it was third for cancer-related death. ${ }^{46}$ Between 2010 and 2014, West Virginia was tied for the highest prevalence of diabetes, ranked highest in the prevalence of asthma, and ranked highest in hospitalizations related to chronic pulmonary disease and end-stage renal disease. ${ }^{47}$ The third factor we think may be relevant is the use of addictive medications by the population. There are no studies we are aware of comparing the rates of use of addictive substances per state to the level of burnout in the state. There is evidence from a Canadian study that there is a link between physician burnout and managing patients with chronic pain with opioids. This ethnographic study described providers as being most frustrated when dealing with patients who were burdened with addiction, mental health problems, and poverty. ${ }^{48}$ We theorize that burnout in a population of primary care providers may be partly explained in the context of the population they serve. The idea is that providers are affected by the burdens of those they care 
for and that these burdens have an accumulative effect, possibly even a synergistic effect. We think that further research into the accumulative effect of poverty rates, average medical comorbidity, and incidence of substance use disorder on the burnout level of providers within each state could provide useful knowledge.

\section{AGE}

Primary care providers in West Virginia were significantly younger than the US as a whole. This would predict higher levels of burnout. Although being older has been associated with less burnout in West Virginia and the US, it is not clear whether this is cause or effect. Burnout is lowest in late-career physicians who are less likely to have work-life conflicts that would result in burnout and might also be the product of a selection process in which physicians with more burnout tend to retire earlier. ${ }^{34}$ To answer this, longitudinal studies that followed cohorts with low and high burnout at baseline to compare whether they retired earlier or later would be required.

\section{RURAL/URBAN}

Rural versus urban practice location affected burnout, although the only significant difference was in comparing physicians to APRNs/ PAs in rural areas; being rural was associated with increased burnout in physicians and reduced burnout in APRNs/PAs. This result was not expected based on previous research showing rurality was protective for physicians. ${ }^{49,50} \mathrm{~A}$ possible explanation for this is that rural areas differ in many of the other variables associated with burnout. Future research into what differs between rural areas with high and low burnout could provide insight that leads to actionable knowledge.

\section{PRACTICE TYPE}

There was no significant association between practice type and burnout within our subjects. However, West Virginia had significantly fewer providers in private practice than the US in general. We speculate that this difference relates to a higher poverty level in West Virginia.

\section{WORK HOURS}

Burnout increased in a significant linear manner as the number of work hours increased in our study group. This finding is consistent with a sample of US physicians that identified increasing work hours as associated with severe burnout. ${ }^{37} \mathrm{~A}$ controlled trial could be helpful to establish whether reducing work hours translates to less burnout. Although this seems intuitive, there is a possibility that burnout reduces efficiency thus driving up work hours.

\section{PROVIDER TYPE}

The provider type is a significant factor in burnout. Physicians in our study are more likely to be burned out than APRNs/PAs (odds ratio 2.89 and $p=0.039$ ). This is partly explained by work hour differences. The odds ratio for working $>50$ hours/week in physician to APRNs/PAs is 3.32 ( $p$ $=0.022$ ). This is also consistent with the common thread of emotional exhaustion, which is the only domain on the $\mathrm{MBI}$ where these providers differ significantly and is the domain most associated with work hours. However, work hours are not likely the only factor. When looking only at providers who work less than 50 hours/week, physicians are still burned out more than APRNs/ Pas, which would indicate that work hours do not entirely explain this. Risk of a malpractice claim is one variable that differs between these provider types. The odds of having a malpractice case are 9.4 times higher for physicians than for APRNs/PAs, ${ }^{51}$ which could add to burnout due to the link between recent malpractice and burn- 
out. ${ }^{52}$ It is also feasible that there are educational or cultural differences between these provider types. It has been shown that the physician medical education process is associated with a decline in mental health profiles in students..$^{53}$

\section{SELF-RATING OF BURNOUT}

The significant association between the subjects' self-rating of burnout and the MBI results could be used as a simple way to screen for burnout and confirms that our subjects had fair insight into their condition. If we were to use a self-rating of mild or higher as opposed to no burnout as a threshold, self-rating would have a sensitivity of $94.74 \%$ in our study.

\section{LIMITATIONS}

Study limitations include a smaller sample size in general (especially of APRN/PAs), a concerted focus on primary care providers, and limited scope in terms of data obtained from one geographical region. We were also limited in not knowing for sure how many invitations went out due to the inability to anticipate that email invitations would be forwarded. However, this study does provide focus on an essential component of the healthcare workforce in a state with complex social determinants of health.

\section{CONCLUSION}

This study finds severe burnout to be significantly more prominent in West Virginia primary care physicians compared to US physicians in general and insignificantly higher compared to US primary care physicians. This is partly explained by having a higher female to male ratio, a younger population of physicians, very high rates of poverty, and one of the highest rates of medical comorbidity in the US. Severe burnout was significantly more common in physicians than in APRN/PAs, partly due to physicians working more as there was a strong linear association between work hours and frequency of severe burnout. A single question, the subject's self-rating of burnout, was shown to have high sensitivity for detecting burnout. This could be used as a rapid screening tool for burnout in primary care. Further investigation is needed regarding the relationship between provider burnout and the accumulative burdens of those they serve, including poverty, medical comorbidity, and mental health/substance abuse.

\section{AUTHOR AFFILIATION}

1. Marshall University Joan C. Edwards School of Medicine, Huntington, West Virginia,

2. West Virginia University School of Public Health

\section{REFERENCES}

1. Dandar VM, Grigsby Kevin, Bunton Sarah, Burnout Among U.S. Medical School Faculty, Analysis in Brief. 2019: Volume19, Number1. Association of American Medical Colleges

2. Pines $A$, Maslach $C$. Characteristics of staff burnout in mental health settings. Hosp Community Psychiatry. 1978;29(4):233-237.

3. Maslach C JS, Leiter M. . Maslach Burnout Inventory Manual. 1996.

4. Hall LH, Johnson J, Watt I, Tsipa A, O'Connor DB. Healthcare Staff Wellbeing, Burnout, and Patient Safety: A Systematic Review. PloS one. 2016;11(7):e0159015-e0159015.

5. Panagioti M, Geraghty K, Johnson J, et al. Association Between Physician Burnout and Patient Safety, Professionalism, and Patient Satisfaction: A Systematic Review and Meta-analysis. JAMA internal medicine. 2018.

6. Shanafelt TD, Balch CM, Bechamps G, et al. Burnout and medical errors among American surgeons. Annals of surgery. 2010;251(6):995-1000.

7. Fahrenkopf AM, Sectish TC, Barger LK, et 
al. Rates of medication errors among depressed and burnt out residents: prospective cohort study. BMJ (Clinical research ed). 2008;336(7642):488-491.

8. Tawfik DS, Profit J, Morgenthaler TI, et al. Physician Burnout, Well-being, and Work Unit Safety Grades in Relationship to Reported Medical Errors. Mayo Clinic proceedings. 2018;93(11):1571-1580.

9. Anagnostopoulos F, Liolios E, Persefonis G, Slater J, Kafetsios K, Niakas D. Physician burnout and patient satisfaction with consultation in primary health care settings: evidence of relationships from a one-withmany design. Journal of clinical psychology in medical settings. 2012;19(4):401-410.

10. Ahola K, Vaananen A, Koskinen A, Kouvonen A, Shirom A. Burnout as a predictor of allcause mortality among industrial employees: a 10-year prospective register-linkage study. J Psychosom Res. 2010;69(1):51-57.

11. Shanafelt TD, Balch CM, Dyrbye L, et al. Special report: suicidal ideation among American surgeons. Arch Surg. 2011;146(1):54-62.

12. Pompili $M$, Innamorati $M$, Narciso V, et al. Burnout, hopelessness and suicide risk in medical doctors. Clin Ter. 2010;161(6):511514.

13. Lafreniere JP, Rios R, Packer $H$, Ghazarian S, Wright SM, Levine RB. Burned Out at the Bedside: Patient Perceptions of Physician Burnout in an Internal Medicine Resident Continuity Clinic. Journal of general internal medicine. 2016;31(2):203-208.

14. Brown SD, Goske MJ, Johnson CM. Beyond substance abuse: stress, burnout, and depression as causes of physician impairment and disruptive behavior. Journal of the American College of Radiology : JACR. 2009;6(7):479-485.

15. Schernhammer ES, Colditz GA. Suicide rates among physicians: a quantitative and gender assessment (meta-analysis). The American journal of psychiatry. 2004;161(12):22952302.

16. Shanafelt T, Goh J, Sinsky C. The Business
Case for Investing in Physician Well-being. JAMA internal medicine. 2017;177(12):18261832.

17. Buchbinder SB, Wilson M, Melick CF, Powe NR. Primary care physician job satisfaction and turnover. Am J Manag Care. 2001;7(7):701713.

18. Sibbald B, Bojke C, Gravelle H. National survey of job satisfaction and retirement intentions among general practitioners in England. BMJ (Clinical research ed). 2003;326(7379):22.

19. Landon BE, Reschovsky JD, Pham HH, Blumenthal D. Leaving medicine: the consequences of physician dissatisfaction. Medical care. 2006;44(3):234-242.

20. Hamidi MS, Bohman B, Sandborg C, et al. Estimating institutional physician turnover attributable to self-reported burnout and associated financial burden: a case study. BMC health services research. 2018;18(1):851.

21. Shanafelt TD, Raymond $M$, Kosty $M$, et al. Satisfaction with work-life balance and the career and retirement plans of US oncologists. Journal of clinical oncology : official journal of the American Society of Clinical Oncology. 2014;32(11):1127-1135.

22. Shanafelt T, Sloan J, Satele D, Balch C. Why do surgeons consider leaving practice? Journal of the American College of Surgeons. 2011;212(3):421-422.

23. Dewa CS, Loong D, Bonato S, Thanh NX, Jacobs P. How does burnout affect physician productivity? A systematic literature review. BMC health services research. 2014;14:325.

24. Bates DW, Spell N, Cullen DJ, et al. The costs of adverse drug events in hospitalized patients. Adverse Drug Events Prevention Study Group. Jama. 1997;277(4):307-311.

25. Friedberg MW, Chen PG, Van Busum KR, et al. Factors Affecting Physician Professional Satisfaction and Their Implications for Patient Care, Health Systems, and Health Policy. Rand health quarterly. 2014;3(4):1.

26. Babbott S, Manwell LB, Brown R, et al. Electronic medical records and physician stress in 
primary care: results from the MEMO Study. Journal of the American Medical Informatics Association : JAMIA. 2014;21(e1):e100-106.

27. O'Malley AS, Grossman JM, Cohen GR, Kemper NM, Pham $\mathrm{HH}$. Are electronic medical records helpful for care coordination? Experiences of physician practices. Journal of general internal medicine. 2010;25(3):177-185.

28. Lee RT, Seo B, Hladkyj S, Lovell BL, Schwartzmann L. Correlates of physician burnout across regions and specialties: a meta-analysis. Human resources for health. 2013;11:48.

29. Linzer M, Poplau S, Babbott S, et al. Worklife and Wellness in Academic General Internal Medicine: Results from a National Survey. Journal of general internal medicine. 2016.

30. Brazeau CM, Shanafelt T, Durning SJ, et al. Distress among matriculating medical students relative to the general population. Academic medicine : journal of the Association of American Medical Colleges. 2014;89(11):1520-1525.

31. Dyrbye LN, West CP, Sinsky CA, Goeders LE, Satele DV, Shanafelt TD. Medical Licensure Questions and Physician Reluctance to Seek Care for Mental Health Conditions. Mayo Clinic proceedings. 2017;92(10):1486-1493.

32. Wiederhold BK, Cipresso P, Pizzioli D, Wiederhold M, Riva G. Intervention for Physician Burnout: A Systematic Review. Open Med (Wars). 2018;13:253-263.

33. Olson K, Kemper KJ, Mahan JD. What factors promote resilience and protect against burnout in first-year pediatric and medicine-pediatric residents? Journal of evidence-based complementary \& alternative medicine. 2015;20(3):192-198.

34. Dyrbye LN, Varkey P, Boone SL, Satele DV, Sloan JA, Shanafelt TD. Physician satisfaction and burnout at different career stages. Mayo Clinic proceedings. 2013;88(12):1358-1367.

35. Shanafelt TD, Mungo M, Schmitgen J, et al. Longitudinal Study Evaluating the Association Between Physician Burnout and Changes in Professional Work Effort. Mayo Clinic proceedings. 2016;91(4):422-431.
36. West Virginia Alliance for Creative Health Solutions. 2020.

37. Shanafelt TD, West $C P$, Sinsky $C$, et al. Changes in Burnout and Satisfaction With Work-Life Integration in Physicians and the General US Working Population Between 2011 and 2017. Mayo Clinic proceedings. 2019.

38. Maslach C JS. Maslach Burnout Inventory.

39. Vetter TR, Mascha EJ. Bias, Confounding, and Interaction: Lions and Tigers, and Bears, Oh My! Anesth Analg. 2017;125(3):1042-1048.

40. Osborn M, Satrom J, Schlenker A, Hazel M, Mason M, Hartwig K. Physician assistant burnout, job satisfaction, and career flexibility in Minnesota. Jaapa. 2019;32(7):41-47.

41. Coplan B, McCall TC, Smith N, Gellert VL, Essary AC. Burnout, job satisfaction, and stress levels of PAs. Jaapa. 2018;31(9):42-46.

42. Eley E, Jackson B, Burton C, Walton E. Professional resilience in GPs working in areas of socioeconomic deprivation: a qualitative study in primary care. Br J Gen Pract. 2018;68(677):e819-e825.

43. O'Brien R, Wyke S, Guthrie B, Watt G, Mercer S. An 'endless struggle': a qualitative study of general practitioners' and practice nurses' experiences of managing multimorbidity in socio-economically deprived areas of Scotland. Chronic Illn. 2011;7(1):45-59.

44. Percent of Total Population in Poverty. USDA. 2018.

45. U.S. Bureau Of Labor Statistics. 2020.

46. Stats of the State of West Virginia. 2017.

47. Raghupathi W, Raghupathi V. An Empirical Study of Chronic Diseases in the United States: A Visual Analytics Approach. International journal of environmental research and public health. 2018;15(3).

48. Webster F, Rice K, Katz J, Bhattacharyya O, Dale C, Upshur R. An ethnography of chronic pain management in primary care: The social organization of physicians' work in the midst of the opioid crisis. PloS one. 2019;14(5):e0215148-e0215148.

49. Hogue A, Huntington MK. Family Physician Burnout Rates in Rural versus Metropolitan 
Areas: A Pilot Study. S D Med. 2019;72(7):306308.

50. Saijo Y, Chiba S, Yoshioka E, et al. Job stress and burnout among urban and rural hospital physicians in Japan. Aust J Rural Health. 2013;21(4):225-231.

51. Brock DM, Nicholson JG, Hooker RS. Physician Assistant and Nurse Practitioner Malpractice Trends. Med Care Res Rev. 2017;74(5):613624.

52. Balch CM, Oreskovich MR, Dyrbye LN, et al. Personal consequences of malpractice lawsuits on American surgeons. Journal of the American College of Surgeons. 2011;213(5):657-667.

53. Shanafelt TD, Hasan O, Dyrbye LN, et al. Changes in Burnout and Satisfaction With Work-Life Balance in Physicians and the General US Working Population Between 2011 and 2014. Mayo Clinic proceedings. 2015;90(12):1600-1613. 